\title{
Towards Standardization of Deregulated Electricity Market Communications in Nigeria
}

\author{
Joseph O. Dada \\ Department of Electrical and Computer Engineering \\ Faculty of Engineering \\ Elizade University, Nigeria
}

\begin{abstract}
The separation of vertically integrated electric power utility in Nigeria into independent entities has opened up the requirement for information and data exchange among the new entities not only to guarantee the security and reliability of the power network, but also for accounting purposes. However, information exchange in highly heterogeneous computing environment poses a major difficulty due to different applications, databases and data models of these entities. This work presents a Unified Nigerian Electricity Market Information Model called UNEMIM to overcome this difficulty. UNEMIM specifies a uniform way for describing and communicating electricity market data. The UNEMIM object model and XML Schema generated from the model are presented along with application examples. A unified information model will provide a common language for describing information and data in Nigeria deregulated electricity market. This will eliminate the requirement for data mapping from multiple sources thereby overcoming the challenge of an in depth understanding of several data sources from the different stakeholders in the electricity market in Nigeria.
\end{abstract}

\section{General Terms}

Electricity market communications, standardization

\section{Keywords}

Data Communications, Unified Information Model, Objectoriented Method, Message Syntax, XML

\section{INTRODUCTION}

Nigeria in her quest to solve her electricity challenge has taken a giant leap into unknown territory by opening up her electricity power sector into competition through the Electricity Power Sector Reform Act (EPSA) of 2005 [1]. The vertically integrated utility Power Holding Company of Nigeria (PHCN) has been unbundled into 18 successor companies, including 11 Distribution Companies (Discos), 6 Generation Companies and a Transmission Company of Nigeria (TCN) [2]. Many Independent Power Producers (IPPs) have also been licensed (hereafter the 6 Generation companies and IPPs are jointly referred to as Gencos). The selling and handling over of the assets of the PHCN to the successor companies mark the beginning of competition in Nigeria electricity market. Nigerian Electricity Bulk Trader (NBET) was also created to support the initial take off of the competitive electricity market during the transitional period.

The introduction of competition into Nigeria electricity market however brings with it enormous responsibilities from all the stakeholders. One of these responsibilities is the requirement for information and data interchange. The separation of the vertically integrated PHCN into independent entities makes it mandatory for the different entities to interact and exchange information and data not only for the management and monitoring of system security and reliability, but also for the accounting and settlement purposes [3]. The newly created actors in the Nigeria electricity market will therefore need to automate communication with one another. The information and data exchange requirements are well documented in the Grid Code [4], Distribution Code [5], Metering Code [6] and Market Rules [7]. The exchange of meter data between the Market Operator (MO) and the other actors such as the Gencos and Dis$\cos$ is an excellent example of these requirements. Information exchange will be enabled by several applications needed for fulfilling the functions and roles of the actors in the deregulated electricity market environment. These applications are either inherited from the assets of the PHCN or will be newly acquired or developed.

Unified data model and standardized data exchange format will therefore play very significant role in the automation of information exchange for both inter-applications and inter-corporations. It is very inappropriate to align data model to the individual application or enterprise data model. Such approach will lack uniformity and will only consider functional requirement of the respective applications or corporations. It is only through the concepts of domain objects that a unified, application independent, and consistent data models can be created and maintained [8]. Inter-enterprise data exchange requires common data model and agreed standardized exchanging format to prevent the development of multiple message models. A seamless integration of market actors' proprietary information requires a standard way for describing the electricity market entities, their attributes, and relationships.

The important role of information exchange in electric power network operations led to the adoption of Common Information Model (CIM) as standard to exchange and manage network models by many electricity utilities all over the world [9], [10], [11], [12], [13] and [14]. There are also efforts to extend CIM to support electricity market communications [15] and [16]. While the CIM standard can be adapted to cater for the exchange of network models in Nige- 
rian electricity market environment, the information model for the market operations needs to be tailored towards the adopted market models in Nigeria as defined in Market Rules and Grid Code [17].

The need for a common information model to support information exchange network infrastructure in Nigerian electricity market environment has been emphasized in [18] and [19]. Here, a new Unified Nigerian Electricity Market Information Model (UNEMIM) intended to specify a uniform way for describing and communicating electricity market data in Nigerian electricity market environment is proposed. The main goal is to provide a unified language that describes the data and entity types, the semantics, and the entities involved in market operations [15]. UNEMIM is envisioned to be a means of specifying any kind of quantitative data in the context of deregulated electricity market in Nigeria. It is hoped that this will provide a good starting point for the standardization of the electricity market communications in Nigeria. The rest of this paper is organized as follows: Section 2 presents the electricity market models, requirements for data communication and the unified information models for electricity market communications using object-oriented methods and eXtensible Markup Language (XML). In section 3, some examples describing how to encode electricity market data in XML document are presented and discussed. The paper ends with conclusion in section 4 .

\section{METHODS}

The task of developing UNEMIM model is solely rest on answering the following three questions:

(1) What to model?

(2) What modeling method to use?

(3) What message syntax to use for describing the instance data to be exchanged by the actors?

The answer to the first question lies in the adopted electricity market model and its associated data as documented in the Grid Code, Distribution code, Metering code and Market Rules. ObjectOriented Method (OOM) [20] is adopted to tackle the second question, while XML language [21] is chosen to address the third question. A basic understanding of OOM and XML is assumed but readers are advised to consult [20], [21], [22] and [23] for detailed description of these technologies. This section described in details how these questions are addressed.

\subsection{Market Models and Data Communication Requirements}

The operation of the electricity market in Nigeria after the handing over of the assets of the PHCN to the successor companies is now in the hand of several actors. The actors are the main users of the UNEMIM language. Understanding the market models and the data communication requirements is the key to the modeling and specification of UNEMIM language. Here the Nigeria electricity market models and the data communication requirements in the deregulated electricity market are briefly described.

2.1.1 Nigeria Electricity Market Models. Nigeria electricity market is structured to follow a Single Buyer Model initially during the transitional period. In this model, the Bulk Trader - Nigerian Bulk Electricity Trading Company (NBTCO) is responsible for buying electricity generation from the Gencos and resells this to the Discos that are responsible for supplying the consumers in their respective geographical zone. Single buyer model is a transitional arrangement to assure the Gencos that they will be paid for power pro-

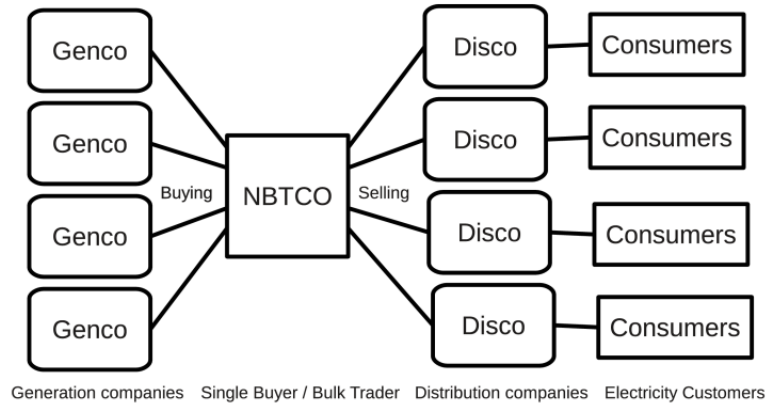

Fig. 1. Schematic representation of the single buyer model.

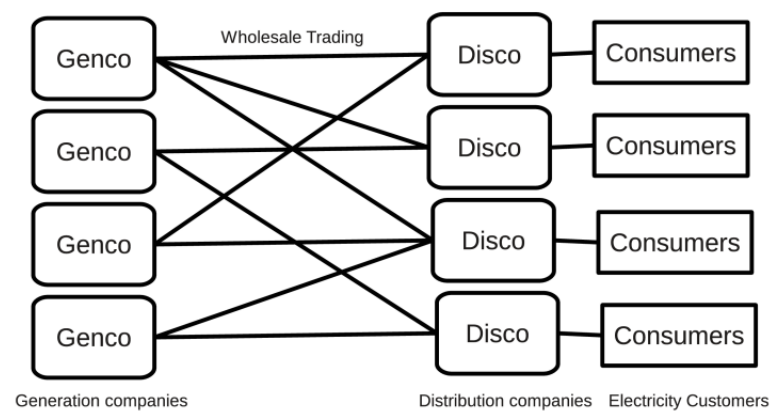

Fig. 2. Schematic representation of wholesale model.

duced and supplied to the Discos. Wholesale competition model that allows direct electricity trading between the Gencos and Discos is expected to take over from the single buyer model after transitional electricity market arrangement [19]. Fig. 1 and 2 show the schematic representations of the single buyer and wholesale market model respectively.

2.1.2 Data Communication Requirements. The basic steps for operating the electricity market models include buying and selling, signing of contracts of agreement, execution of the contracts, i.e. actual physical delivery of electricity energy, metering and accounting. All the necessary data needed to be exchanged in order to fulfill all these steps are specified in the Market Rules and Grid, Distribution and Metering Codes. These include metering data, contract nominations, load profile, imbalance quantity profile, etc. The information provided in these Codes and Rules combined with the market models described above provide the various data and entity types, the semantics, and the entities to be captured in UNEMIM.

\subsection{Object-Oriented Model of UNEMIM}

Here the UNEMIM model is described using the adopted OOM with Universal Modeling Language (UML) [24]. The UNEMIM object model (UNEMIM-OM) is subdivided into three components: energy data, organization and contract. The top level classes consist of the three main components of UNEMIM-OM as shown in Fig. 3 The abstract class DataObject provides a means of specifying a common attributes on all the elements of UNEMIM. The models of the three components are described in more detail below.

2.2.1 Organization. The organizations are the stakeholders involved in exchanging information and data in the electricity mar- 


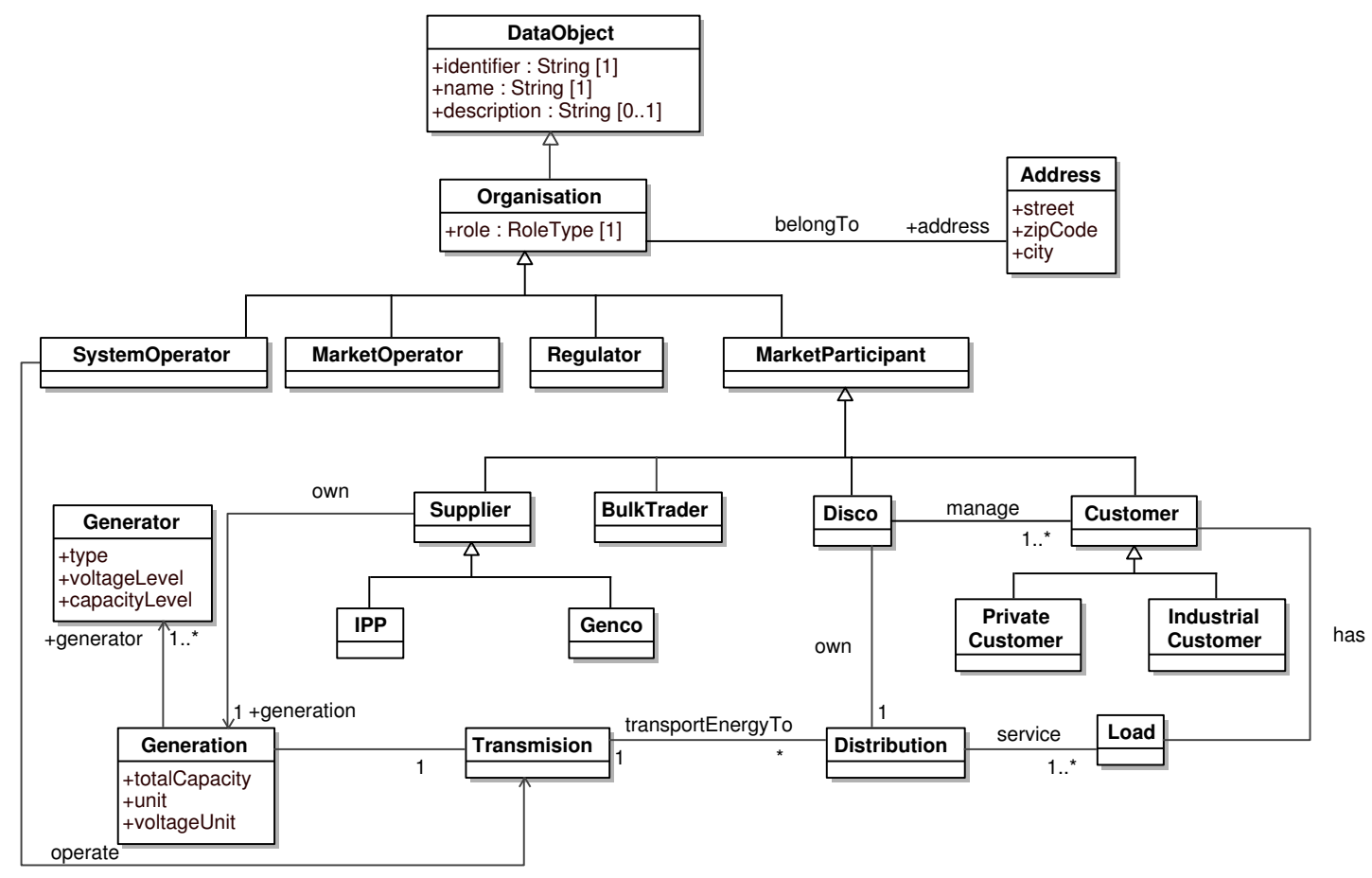

Fig. 4. Organization object model.

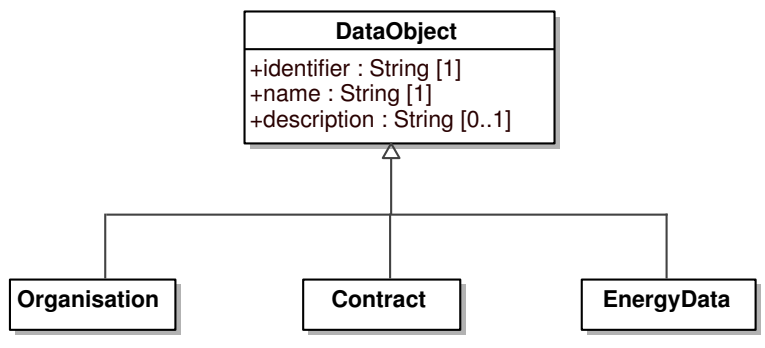

Fig. 3. Top-level classes of UNEMIM-OM.

ket. They include the MO, System Operator (SO), the regulator, the Market Participants (MPs). MPs consist of the suppliers (Gencos and IPPs), NBTCO (Bulk Trader), Discos and customers. The suppliers own the generation stations that supply power to the transmission network, the SO operates the transmission system and Discos own the distribution networks that service the load consumed by the consumers. The overall responsibility of SO and MO is to provide non-discriminatory and efficient system operation and market administration services to all MPs, while the MPs are involved with electricity market operations. Fig. 4 shows the object model representing the organizations.

2.2.2 Contract. According to the Market Rules, the MO is expected to establish and maintain a Contract Register in which it will keep contract information disclosed to it by MPs. Any regional trading contract entered into by the MPs is required to be notified to the MO. This component is concerned with contracts for the purchase and sale of energy. It models all the data related to different types of contract such as bilateral, day ahead and Ancillary services. The market models adopted for the electricity market trading are also included in the contract object model as depicted in Fig. 5

2.2.3 Energy Data. The energy data component defines the energy data generated or consumed as a result of execution of contractual agreement between the MPs. Energy data such as meter data, load profile, nominations, imbalance quantities, connection points, etc. are included in this model. This component plays an important role in accounting and settlement. The object model of the energy data is depicted in Fig. 6

\subsection{The Message Syntax}

The application independent information and semantic models captured in UNEMIM-OM need to be assembled into message syntax for describing the instance data. XML Schema [25] is used as the message syntax. Fig. 7 shows a fragment of the UML diagram for the message assembly using classes from UNEMIM-OM. A new UNEMIM class is introduced to serve as a container class for all the elements of UNEMIM. The new class has three required attributes: the xmlns, level and version. The attribute xmlns declares the default XML namespace used within UNEMIM element, while the level and version attributes are used to specify the current level and version of the UNEMIM-XML Schema respectively.

The UNEMIM-XML Schema is derived from UNEMIM-OM semi-automatically with the help of mapping rules for classes and associations. For example, classes and attributes from UNEMIM$\mathrm{OM}$ are converted into elements and attributes in XML Schema respectively. 


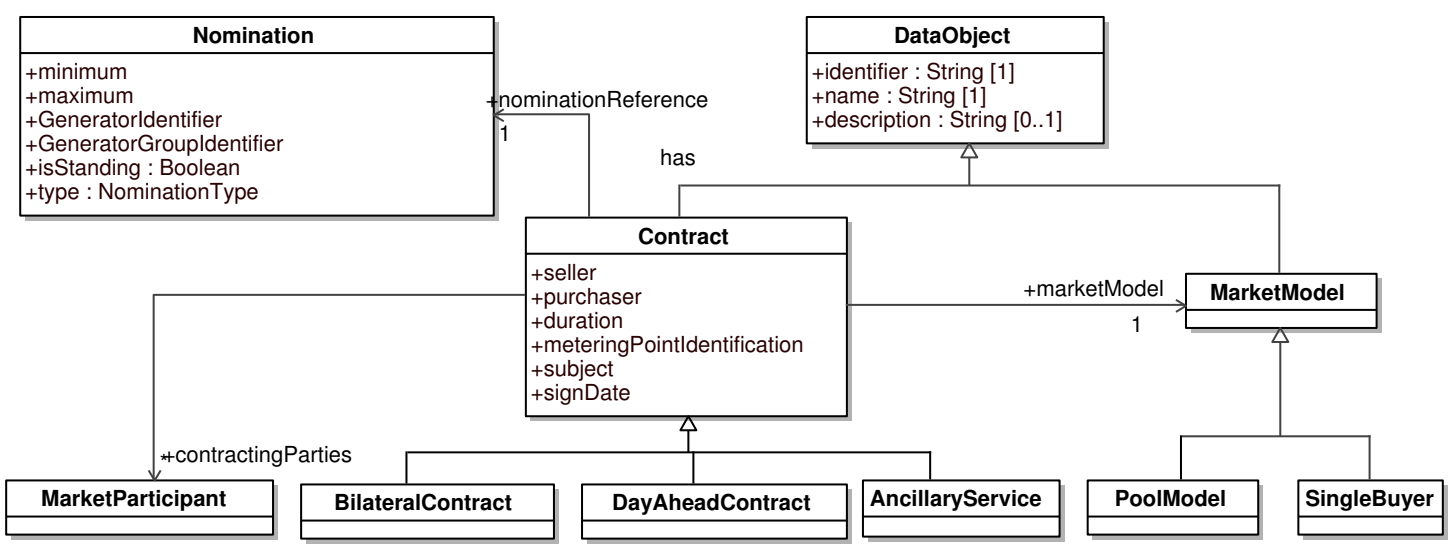

Fig. 5. Contract object model.

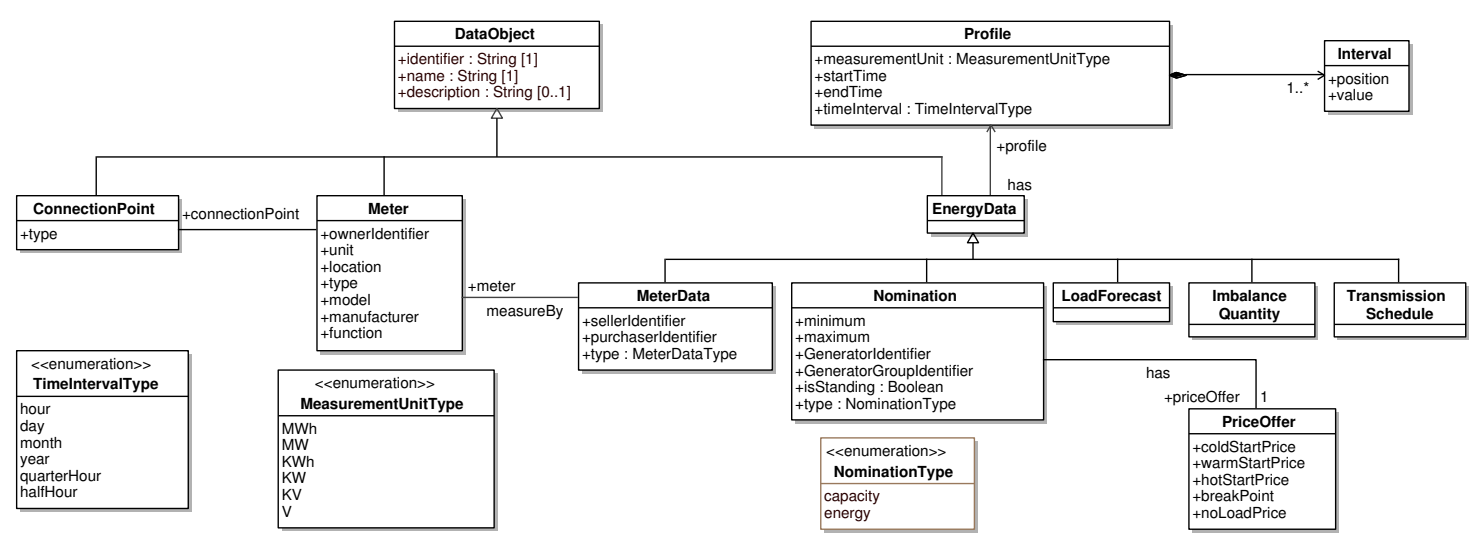

Fig. 6. Energy data object model.

\section{RESULTS AND DISCUSSIONS}

The UNEMIM-XML Schema derived from UNEMIM-OM provides a language for describing and exchanging data in Nigeria electricity market. Fig. 8 shows the fragment of the UNEMIMXML Schema. An instance of the Schema is an instance data in form of UNEMIM-XML document, which is actually exchanged between the actors. UNENIM-XML Schema will normally be kept in a repository. The Schema will serve as a basis for data communication between the actors. All UNEMIM-XML documents received by an actor will be validated against the Schema to check for the conformity of the document with the agreed information format. This section presents and discusses examples of UNEMIM language usage based on the Schema. The examples depend on the type of data that need to be communicated between the stakeholders. They illustrate the breadth of data that can be encoded in UNEMIM language.

\subsection{Example 1 - Organization Data}

The example (Fig. 9) shows data relating to organization involved in electricity market that can be encoded in UNEMIM-XML document. Two Gencos and one Disco are described. The first Genco has three generators with combined total generation capacity of
400MW, while the second Genco has two generators with total generation capacity of $320 \mathrm{MW}$. The third organization encoded in UNEMIM document is a Disco, which is usually a power purchaser, responsible for distributing power to the consumers in the electricity market.

\subsection{Example 2 - Contract Data}

The data encoded in example 1 above describes the MPs that are usually involved in the electricity market operation. Electricity contract including the nominations is required to be registered with the MO by the MPs before the actual execution of the contract as specified in the Market rules. A contract between a Disco identified as DISCO0001 and Genco identified as GENCO0001 is encoded in UNEMIM-XML document in Fig. 10 The example includes the energy nomination that is due to be executed between 00:00 and 24:00 hour on 25-10-2014.

\subsection{Example 3 - Meter Data}

The metering data is the key to the electricity market transactions. The accurate execution of electricity contractual agreement between MPs can only be measured through proper metering infrastructures at the connection points. The measured meter data profile needs to be exchanged with the MO for calculation of imbal- 


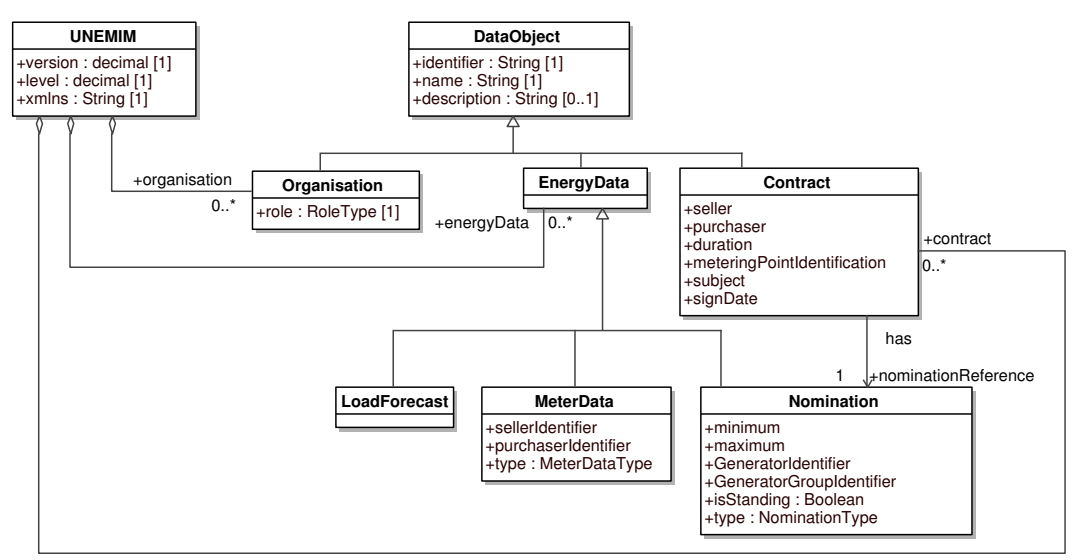

Fig. 7. Fragment of object model for message assembly using UNEMIM-OM classes.

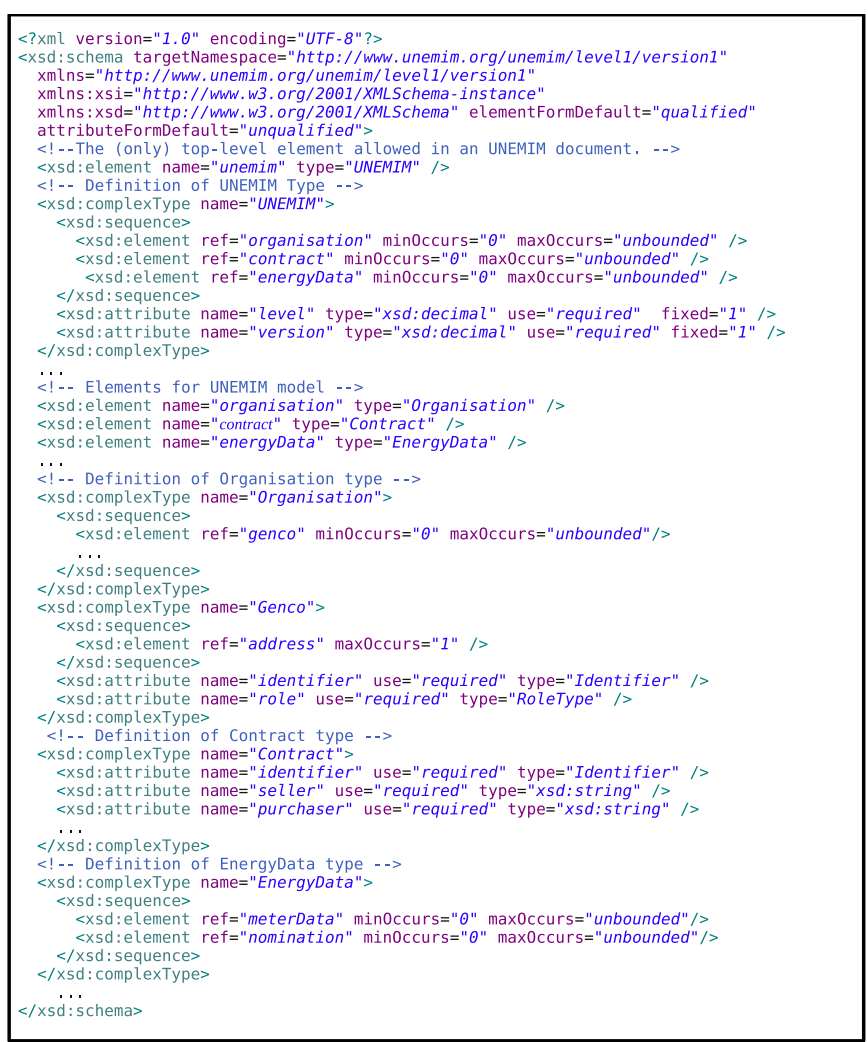

Fig. 8. Fragment of UNEMIM-XML Schema.

ance quantities used for accounting and settlement. The UNEMIMXML document example in Fig. 11 shows an example of the meter data measured after the physical delivery of the contractual power agreement between Disco identified as DISCO0001 and a Genco identified as GENCO0002. Remember the contract data registered with the MO prior to execution of power transmission and the submitted meter data form the basis of the imbalance quantities calculation.

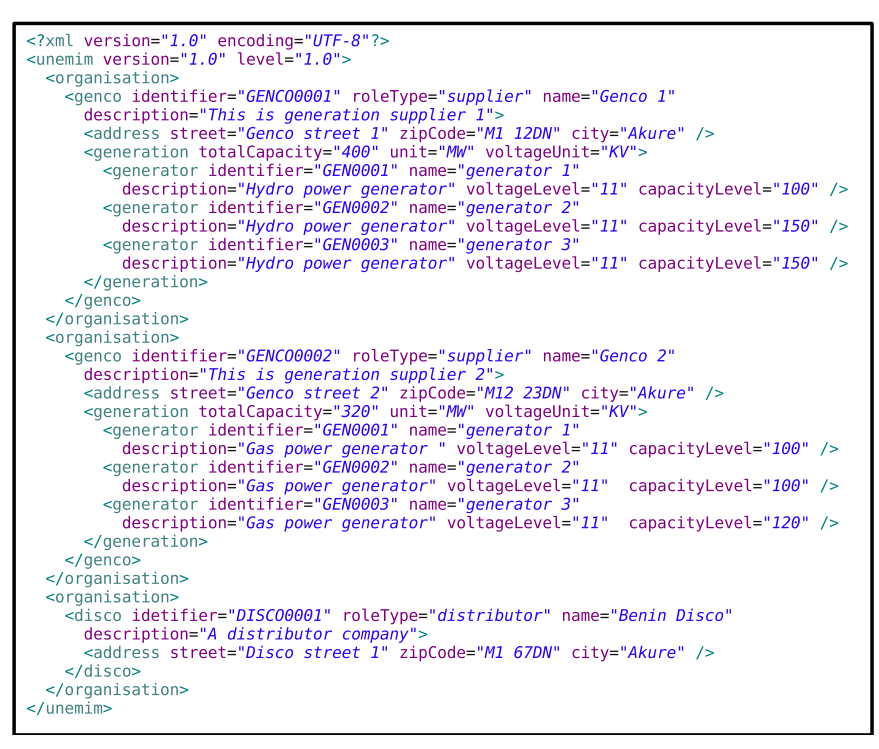

Fig. 9. Example of how to encode organization data in UNEMIM language.

\section{CONCLUSIONS}

The deregulated electricity market in Nigeria has open up new challenges including the need for data and information exchange. The heterogeneous IT environments of the stakeholders in the electricity market will make the data exchange very difficult without a unified data model. This paper presented a unified Nigerian electricity market information model called UNEMIM for addressing this problem. UNEMIM model makes use of OOM with UML to develop a model of the electricity market domain objects and XML for describing the message syntax of the instance data. The UNEMIM-XML Schema generated from the domain object models forms the basis for communicating the deregulated electricity market data in Nigeria. The paper describes the UNEMIM model and the XML Schema. It also presents and discusses the examples of how to encode different electricity market data for communication between the stakeholders. 


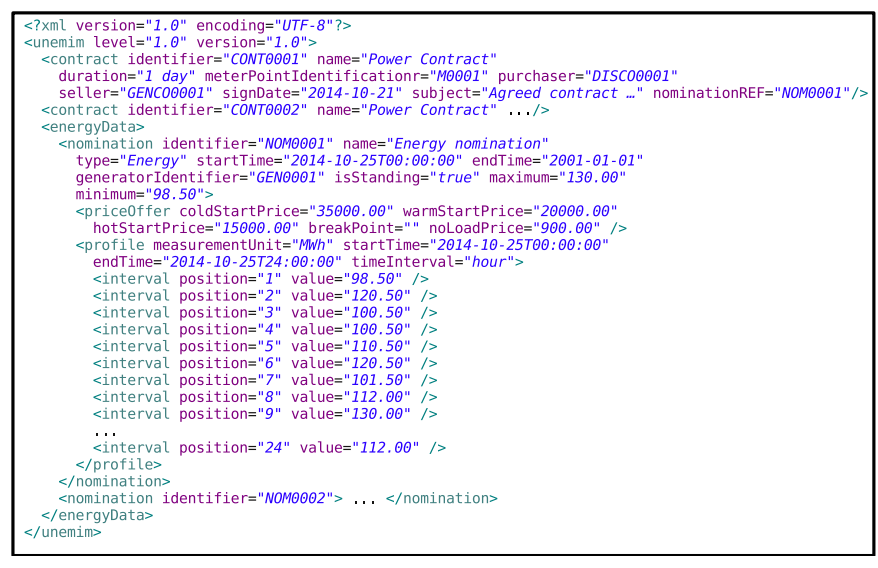

Fig. 10. Example of how to encode electricity contract data in UNEMIM language.

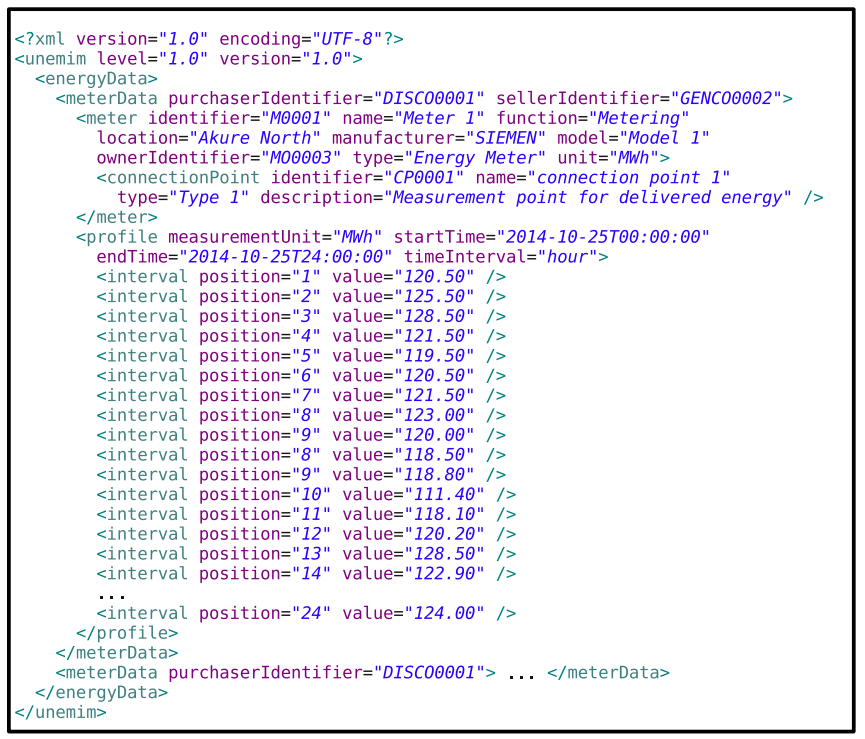

Fig. 11. Example of how to encode meter data in UNEMIM language.

OOM makes it easy to expand and adapt the developed model to new or changed requirements. This is especially important because deregulated electricity market in Nigeria is still evolving and subject to changes during the initial period. Such changes should be possible without changing the existing data models and the applications that use them. These characteristics will also enable UNEMIM to support data communications in distributed electricity generation environment using renewable energy sources as proposed in [2] and [26]. It is hoped that the presented UNEMIM model will generate interests from the research communities and stakeholders in the deregulated electricity market in Nigeria. Such interests will be helpful in the development of a complete and consistent unified information model for the deregulated electricity market in Nigeria. Future work will include the use of the UNEMIM model together with the work presented in [19] to develop a multiagent system infrastructure for data communications in Nigerian deregulated electricity market in Nigeria.

\section{REFERENCES}

[1] Electricity-Act. Nigeria Electricity Reform Act. Technical report, Federal Republic of Nigeria, 2005.

[2] Joseph O. Dada. Towards understanding the benefits and challenges of Smart/Micro-Grid for electricity supply system in Nigeria. Renewable and Sustainable Energy Reviews, 38:1003-1014, October 2014.

[3] J O Dada and H D Kochs. XML-based open electricity market information exchange network using object-oriented methods. International Journal of Computers and Applications, 27(3):153-160, 2005.

[4] Grid-Code. The Grid Code for Nigeria Transmission Systems. Technical report, Nigeria Electricity Regulatory Commission. Available from: http://www.nercng.org/index.php/document-library/funcstartdown/27/, 2005.

[5] Distribution-Code. Distribution Code: The Distribution Code for Nigeria Electricity Distribution System. Technical report, Nigeria Electricity Regulatory Commission. Available from: http://www.nercng.org/index.php/documentlibrary/func-startdown/26/, 2005.

[6] Metering-Code. Nigeria Metering Code. Technical report, Nigeria Electricity Regulation Commission, 2005.

[7] Market-Rules. The Market Rules. Technical report, Nigeria Electricity Regulatory Commission. Available from: http://www.nercng.org/index.php/document-library/funcstartdown/127/, 2005.

[8] J O Dada. Information Exchange Network for the Liberalised Electricity Market with Object-Oriented and Internet-Based Technologies. Fortschritt-Berichte VDI, 2002.

[9] S T Lee. The EPRI common information model for operation and planning. In Proc. IEEE Power Engineering Society Summer Meeting, volume 2, pages 866-871, 1999.

[10] A de Vos, S E Widergren, and J Zhu. XML for CIM model exchange. In Proc. Innovative Computing for Power - Electric Energy Meets the Market. 22nd IEEE Power Engineering Society Int. Conf. Power Industry Computer Applications PICA, pages 31-37, 2001.

[11] Xiaofeng Wang, N N Schulz, and S Neumann. CIM extensions to electrical distribution and CIM XML for the IEEE radial test feeders. IEEE Transactions on Power Systems, 18(3):1021-1028, 2003.

[12] Jialei Xing, Honggeng Yang, and Wenbo Chen. Power System Model Based on CIM and its Application in AVC System Using a CIM Toolkit. In Proc. Asia-Pacific Power and Energy Engineering Conf. (APPEEC), pages 1-4, 2010.

[13] N.N. Schulz and Scott Neumann. CIM extensions to electrical distribution and CIM XML for the IEEE radial test feeders. IEEE Transactions on Power Systems, 18(3):1021-1028, August 2003.

[14] Yemula Pradeep, Jose Thomas, C Laakshmana Sabari, V S K Murthy Balijepalli, S R Narasimhan, and S A Khaparde. Towards usage of CIM in Indian Power Sector. In Proc. IEEE Power and Energy Society General Meeting, pages 1-7, 2011.

[15] Xing Wang and But-Chung Chiu. CIM modeling for Market Management Systems. In Proc. IEEE Power and Energy Society General Meeting, pages 1-5, 2010.

[16] Enamul Haq, Dagmar Haller, Khaled Abdul Rahman, and Becky Iverson. Use of Common Information Model (CIM) 
in Electricity Market at California ISO. In Proc. IEEE Power and Energy Society General Meeting, pages 1-6, 2011.

[17] Joseph O Dada. Conceptual Modelling of Information Exchange Network for Nigeria Deregulated Electricity Market using Object-Oriented Approach. International Journal of Engineering and Technology, 3(4):449-463, 2013.

[18] JO Dada. Information Exchange Framework for Deregulated Electricity Market in Nigeria. International Journal of Engineering and Technology, 2(6):1052-1061, 2012.

[19] Joseph O. Dada. Web-Services-based Architecture for Information Integration in Nigeria Deregulated Electricity Market Environment. International Journal of Computer Applications, 87(13):1-8, February 2014.

[20] J Rumbaugh, M Blaha, W Premerlani, F Eddy, and W Lorensen. Object-Oriented Modeling and Design, volume 38. 1991.

[21] Tim Bray, Jean Paoli, Eve Maler, and Sun Microsystems. Extensible Markup Language (XML) 1.0 (Fifth Edition). W3C Recommendation. Available from: http://www.w3.org/TR/REC-xml, 0:1-37, 2008.

[22] J Rumbaugh, G Booch, and I Jacobson. The Unified Modelling Language Reference Manual. Reading, Mass. AddisonWesley, 1999.

[23] Henry S Thompson, David Beech, Murray Maloney, Noah Mendelsohn, and Lotus Development Corporation. XML Schema Part 1 : Structures Second Edition, 2004.

[24] OMG. UML 2.4.1-Infrastructure Specification, Available from: http://www.omg.org/spec/UML/2.4.1/. Technical report, 2011.

[25] P V Biron and A Malhotra. XML Schema Part 2: Datatypes (W3C Recommendation). World Wide Web Consortium W3C. Available from: http://www.w3.org/TR/xmlschema-2/, 2004.

[26] Abubakar Sadiq Aliyu, Joseph O. Dada. and Ibrahim Khalil Adam. Current status and future prospects of renewable energy in Nigeria. Renewable and Sustainable Energy Reviews, 48:336-346, August 2015. 